\title{
Genes and Pathways in Optic Fissure Closure
}

Authors: Aara Patel ${ }^{1}$, Jane C. Sowden ${ }^{1}$

Address: ${ }^{1}$ Stem Cells and Regenerative Medicine Section, UCL Great Ormond Street Institute of Child Health, University College London, 30 Guilford Street, London, WC1N 1EH UK

Corresponding author: j.sowden@ucl.ac.uk

\section{Abstract}

Embryonic development of the vertebrate eye begins with the formation of an optic vesicle which folds inwards to form a double-layered optic cup with a fissure on the ventral surface, known as the optic fissure. Closure of the optic fissure is essential for subsequent growth and development of the eye. A defect in this process can leave a gap in the iris, retina or optic nerve, known as a coloboma, which can lead to severe visual impairment. This review brings together current information about genes and pathways regulating fissure closure from human coloboma patients and animal models. It focuses especially on current understanding of the morphological changes and processes of epithelial remodelling occurring at the fissure margins.

Key words: Optic fissure, Coloboma, Colobomos, Eye development, Congenital eye malformation

1: Introduction

1.1 Early morphogenesis of the vertebrate eye

1.2 Ocular coloboma is caused when optic fissure closure fails

2. Coloboma disease genes

3. Alignment of fissure margins

3.1 Axial patterning of the optic vesicle and cup

3.2 Invagination and morphogenesis of the optic cup

4. Processes occurring at the fissure margins

4.1 Changes in cell morphology at the optic fissure

4.2 The role of the periocular mesenchyme

4.3 Basement Membrane dissolution and cell adhesion

4.4 Apoptosis at the optic fissure

5. Open Questions

6. Conclusion

\section{Introduction}


The eye is a sensory organ with an intricate and complex organization. It has an early stage of development that achieves the correct three dimensional globe shape and a later stage that involves specification and differentiation of a large variety of cells that make up the various parts of the eye, including the retina. Both stages are regulated by a range of genes and interconnected signalling pathways. This review focuses on optic fissure closure, a process essential for achieving correct morphogenesis of the eye, and the genetic pathways involved.

\subsection{Early morphogenesis of the vertebrate eye}

Vertebrate eye morphogenesis begins with the bilateral evagination of single layered optic vesicles, from the neuroepithelium of the developing brain. As each optic vesicle approaches the surface ectoderm, displacing the intervening mesenchyme, its distal end invaginates to form a double layered optic cup. The inner layer of the optic cup eventually forms the Neural Retina (NR) and the outer layer forms the Retinal Pigmented Epithelium (RPE). Simultaneously, the overlying surface ectoderm invaginates, into the optic cup, to form the lens vesicle. The invagination of the optic vesicle is asymmetrical, such that the dorsal and proximal regions of the vesicle form the outer layer of the optic cup and the ventral and distal regions of the optic vesicle form the inner layer, and a fissure, the optic fissure (also called the choroid fissure), is formed running down the ventral aspect of the cup (Fig $1 \mathrm{~A}$, B). The most proximal region of the vesicle narrows to form the optic stalk, which acts as a path for axons of the optic nerve to reach the brain. The optic fissure allows the hyaloid artery, which supplies the developing lens, to enter the optic cup without having to cross the neuroepithelium [1-3]. The margins of the optic fissure grow towards each other, displace the intervening periocular mesenchyme, until they fuse (Fig $1 \mathrm{C}$ ), leaving a small opening for the hyaloid artery known as the optic disc. In the human foetus, optic fissure closure begins in the $5^{\text {th }}$ week of foetal development and is completed by about the $7^{\text {th }}$ week, corresponding to Carnegie stages 14 to 17 [4]. In mice it begins on embryonic day 11 (E11) and is completed by E13 [5, 6].

\subsection{Ocular coloboma is caused when optic fissure closure fails}

Complete or partial failure of optic fissure closure results in a coloboma; a ventrally located notch or gap in the iris, ciliary body, choroid, retina and/or optic nerve (Fig $1 \mathrm{D}$ ). Coloboma is related to and often associated with microphthalmia (small eyes) [7]. The extent of visual impairment caused by a coloboma ranges from asymptomatic to complete loss of vision, depending on the size and location of the defect. It is estimated to account for $3.2-11.2 \%$ of cases of blindness in children [8] and there is no known cure at present. Various environmental risk factors for Microphthalmia, Anophthalmia 
and Coloboma (MAC), such as maternal Vitamin A deficiency and exposure to drugs, have been suggested but the epidemiological data supporting these is preliminary $[9,10]$. It is likely that most cases have a genetic cause as the defect is seen at birth and has a high sibling recurrence risk of 8.1$13.3 \%[7]$.

This review brings together and integrates up to date information from genetic analysis of human coloboma patients and animal models to construct a complete picture of interacting genes and pathways currently known to be involved in optic fissure closure. This is a developing area of study, which has relevance to both developmental biology and clinical medicine. Coloboma is genetically heterogeneous and the genes mutated in human patients span a wide range of functions, with new ones recently being identified. This review outlines the current state of knowledge of the cellular and genetic mechanisms underlying the closure of the optic fissure. The later part of the review focuses on new insights into the mechanisms of epithelial remodelling at the site of closure.

\section{Coloboma disease genes}

As many as 39 genes have been linked with ocular coloboma in humans. These genes and their associated phenotypes are summarized in Table 1. All have reported monogenic mutations which are proposed to cause coloboma. Some of them are supported by animal models of coloboma with mutations in homologous genes. In addition, variants of uncertain significance in the genes FADD, SCLT1, TBC1D32 and TMX3 have been reported in single cases with syndromic coloboma [11-13]. Additional genes important for fissure closure have been identified in animal models with optic fissure closure defects and are summarized in Table 2 . These have yet to be implicated directly in human eye malformation. Others implicated based on zebrafish Morpholino studies include nlz1, $\mathrm{nlz2}$, Imx1b.1, Imx1b.2 and bcl6, although these have not yet been validated by any germline mutations [14-16]. 


\begin{tabular}{|c|c|c|c|c|c|}
\hline Gene & OMIM Phenotype* & $\begin{array}{l}\text { Coloboma } \\
\text { type }\end{array}$ & $\begin{array}{l}\text { Coloboma disease } \\
\text { alleles reported }\end{array}$ & Supporting animal models & References \\
\hline PAX6 & $\begin{array}{l}\text { Aniridia; Coloboma of Optic Nerve; Coloboma, ocular, autosomal dominant; } \\
\text { Peter's Anomaly and others }\end{array}$ & $\mathrm{I}, \mathrm{R}, \mathrm{Ch}, \mathrm{ON}$ & Multiple & Mouse & [17-19] \\
\hline vSX2 & Microphthalmia, with coloboma 3; Microphthalmia, isolated 2 & I & Multiple & Mouse, Zebrafish MO & [20-27] \\
\hline MAF & Cataract 21, multiple types & 1 & Multiple & Mouse (cataract only) & [28-32] \\
\hline ALDH1A3 & Microphthalmia, isolated 8 & $\mathrm{R}$ & 3 & Mouse & [33-36] \\
\hline TENM3 & Microphthalmia, isolated, with coloboma 9 & I & 2 & No & {$[37,38]$} \\
\hline ABCB6 & Microphthalmia, isolated, with coloboma 7 & $\mathrm{I}, \mathrm{R}, \mathrm{Ch}$ & 2 & No & [39] \\
\hline FZD5 & Microphthalmia, coloboma & $\mathrm{I}, \mathrm{R}, \mathrm{Ch}$ & $\begin{array}{l}1 \text { ( } 2 \text { related } \\
\text { families) }\end{array}$ & Mouse, Zebrafish $\mathrm{MO}+\mathrm{R}$ & {$[40,41]$} \\
\hline SALL2 & Coloboma, ocular, autosomal recessive & $\mathrm{I}, \mathrm{R}, \mathrm{Ch}$ & 1 & Mouse & [42] \\
\hline RAX & Microphthalmia, isolated 3 & ON & 1 & Mouse & [43-45] \\
\hline CRYAA & Cataract 9, multiple types & 1 & 1 & Mouse & [46] \\
\hline RBP4 & $\begin{array}{l}\text { Microphthalmia, isolated, with coloboma 10; Retinal dystrophy, iris coloboma, and } \\
\text { comedogenic acne syndrome (OMIM) }\end{array}$ & 1 & Multiple & No & [47-50] \\
\hline OTX2 & Microphthalmia, Syndromic 5 & I, R & Multiple & No & {$[51,52]$} \\
\hline GDF3 & $\begin{array}{l}\text { Klippel-Feil Syndrome3; Microphthalmia with coloboma 6; Microphthalmia, } \\
\text { isolated } 7\end{array}$ & $\mathrm{I}, \mathrm{R}$ & Multiple & Zebrafish MO & {$[53,54]$} \\
\hline PAX2 & Papillorenal Syndrome & ON & Multiple & Mouse & [55-59] \\
\hline
\end{tabular}




\begin{tabular}{|c|c|c|c|c|c|}
\hline CHD7 & CHARGE syndrome & I, R, ON & Multiple & Mouse & [60-62] \\
\hline TFAP2A & Branchiooculofacial syndrome & $\mathrm{I}, \mathrm{C}$ & Multiple & Mouse, Zebrafish MO & [63-68] \\
\hline PIGL & CHIME syndrome & $\mathrm{R}$ & Multiple & No & [69] \\
\hline АСТВ & Baraitser-Winter syndrome 1 & $\mathrm{I}, \mathrm{R}$ & Multiple & No & [70] \\
\hline ACTG1 & Baraitser-Winter syndrome 2 & $\mathrm{I}, \mathrm{R}$ & Multiple & No & [70] \\
\hline MAB21L2 & Microphthalmia, syndromic 14 & $\mathrm{I}, \mathrm{R}$ & Multiple & Mouse, Zebrafish & [71-73] \\
\hline ZEB2 & Mowat-Wilson syndrome & $\mathrm{I}, \mathrm{R}$ & Multiple & No & {$[74-76]$} \\
\hline YAP1 & $\begin{array}{l}\text { Coloboma, ocular, with or without hearing impairment, cleft lip/palate, and/or } \\
\text { mental retardation }\end{array}$ & $\mathrm{I}, \mathrm{R}, \mathrm{Ch}$ & 3 & Zebrafish & {$[77-79]$} \\
\hline sox2 & Microphthalmia, syndromic 3 & $\mathrm{I}, \mathrm{R}, \mathrm{Ch}$ & 3 & Mouse & $\begin{array}{l}\text { [80-84](not exhautive } \\
\text { list) }\end{array}$ \\
\hline$H M X 1$ & Oculoauricular syndrome & $\mathrm{I}, \mathrm{R}, \mathrm{Ch}$ & 2 & Mouse, Zebrafish MO & {$[85-87]$} \\
\hline BCOR & Microphthalmia, syndromic 2 & 1 & 2 & Zebrafish MO & [88-90] \\
\hline MITF & COMMAD syndrome & 1 & 2 & Mouse & {$[91,92]$} \\
\hline C12ORF57 & Temtamy syndrome & $\mathrm{I}, \mathrm{R}, \mathrm{Ch}$ & 1 (in 3 families) & No & [93-95] \\
\hline SMOC1 & Microphthalmia with limb anomalies & $\mathrm{R}$ ? & 1 & Mouse & {$[96,97]$} \\
\hline SHH & Microphthalmia with coloboma 5; Holoprosencephaly 3 & $\mathrm{I}, \mathrm{R}$ & 1 & Mouse, Zebrafish & [98-101] \\
\hline GDF6 & $\begin{array}{c}\text { Klippel-Feil Syndrome 1; Microphthalmia with coloboma 6, digenic (with GDF3); } \\
\text { Microphthalmia, isolated } 4\end{array}$ & $\mathrm{I}, \mathrm{R}, \mathrm{Ch}, \mathrm{ON}$ & 1 & Mouse, Zebrafish, Zebrafish MO & [102-104] \\
\hline
\end{tabular}




\begin{tabular}{|c|c|c|c|c|c|}
\hline SEMA3E & CHARGE syndrome & I, R, ON & 1 & No & [105] \\
\hline SIX3 & Holoprosencephaly 2 & $\mathrm{I}, \mathrm{R}, \mathrm{Ch}$ & 1 & No & {$[106,107]$} \\
\hline PTCH1 & Holoprosencephaly 7 & 1 & 1 & Zebrafish & {$[108,109]$} \\
\hline SRD5A3 & Kahrizi Syndrome & 1 & 1 & No & [110] \\
\hline PQBP1 & Renpenning syndrome & $\mathrm{R}, \mathrm{Ch}, \mathrm{OD}$ & 1 & No & [111] \\
\hline IGBP1 & $\begin{array}{l}\text { Corpus callosum, agenesis of, with mental retardation, ocular coloboma and } \\
\text { micrognathia }\end{array}$ & I, ON & 1 & No & [112] \\
\hline BMP7 & $\begin{array}{l}\text { Microphthalmia, anophthalmia, systemic abnormalities, intellectual disability (not } \\
\text { on OMIM) }\end{array}$ & $\mathrm{R}, \mathrm{Ch}, \mathrm{ON}$ & 1 & Mouse & {$[113,114]$} \\
\hline HMGB3 & ?Microphthalmia, syndromic 13 & $\mathrm{I}, \mathrm{R}, \mathrm{Ch}$ & 1 & Xenopus MO+R & [115] \\
\hline PDE6D & ?Joubert syndrome 22 & ON & 1 & Zebrafish $\mathrm{MO}+\mathrm{R}$ & [116] \\
\hline SALL1 & Townes-Brocks syndrome 1 & Ch, R & 1 & Mouse & {$[117,118]$} \\
\hline MSX2 & Coloboma, craniosynostosis and syndactyly & $\mathrm{I}, \mathrm{R}, \mathrm{Ch}$ & 1 & Mouse & {$[119,120]$} \\
\hline
\end{tabular}

Table 1 Human Coloboma disease genes: I: Iris, R: Retina, Ch: Choroid, ON: Optic Nerve, MO: Morpholino, MO+R: Morpholino followed by rescue

experiment with WT allele. Morpholino knockdown models without replication by genetic lesions are considered unproven. Green: Isolated eye phenotype. Orange: Eye phenotype with systemic defects, ${ }^{*}$ http://omim.org/. 
Table2: Genes identified from animal models of coloboma

\begin{tabular}{|c|c|c|c|c|}
\hline Gene & Species & Genotype & Phenotype & Reference \\
\hline $\operatorname{Vax} 1$ & Mouse & Vax1-/- & $\begin{array}{c}\text { Coloboma, optic nerve } \\
\text { dysgenesis, cleft palate, brain } \\
\text { defects }\end{array}$ & [121] \\
\hline $\operatorname{Vax} 2$ & Mouse & $\operatorname{Vax} 2-/-$ & Coloboma & [122] \\
\hline Cdon & Mouse & Cdon -/- & $\begin{array}{c}\text { Coloboma, microphthalmia, lens } \\
\text { defects }\end{array}$ & [123] \\
\hline$D k k$ & Mouse & $D k k+/-$ & $\begin{array}{c}\text { Coloboma, Anterior Segment } \\
\text { anomalies }\end{array}$ & [124] \\
\hline$T b \times 2$ & Mouse & $T b \times 2-/-$ & $\begin{array}{l}\text { Microphthalmia, coloboma, } \\
\text { heart defects, embryonic lethal }\end{array}$ & [125] \\
\hline Foxg1 & Mouse & Foxg1-/- & Coloboma & {$[126,127]$} \\
\hline$N r 2 f 1, N r 2 f 2$ & Mouse & $\begin{array}{l}\text { Rax-Cre/+; Nr2f1 } \\
f l / f l ; N r 2 f 2 f l / f l\end{array}$ & Microphthalmia, coloboma & [128] \\
\hline Lrp6 & Mouse & Lrp6-/- & Coloboma & [129] \\
\hline Axin-2 & Mouse & Axin2 -/- & $\begin{array}{c}\text { Microphthalmia, Coloboma, } \\
\text { Lens defects, expanded Ciliary } \\
\text { Margin }\end{array}$ & [130] \\
\hline Pitx2 & Mouse & Pitx2-/- & Microphthalmia, Coloboma & [131] \\
\hline
\end{tabular}




\begin{tabular}{|c|c|c|c|c|}
\hline Imo2 & Zebrafish & Lmo2-/- & Coloboma & [132] \\
\hline Smad7 & Mouse & Smad7-/- & Coloboma, microphthalmia & [133] \\
\hline opo(ofcc1) & Medaka fish & ofcc-/- & Misshapen optic cup, coloboma & [134] \\
\hline Ctnna1 & Mouse & $\begin{array}{c}\text { Six3-Cre; } \\
\text { Ctnna1fx/fx }\end{array}$ & $\begin{array}{c}\text { Colobma, disrupted retinal } \\
\text { organization }\end{array}$ & [135] \\
\hline $\operatorname{cdh} 2$ (ncad) & Zebrafish & cdh2 -/- & $\begin{array}{l}\text { Colobma, disrupted retinal } \\
\text { lamination }\end{array}$ & [136] \\
\hline Fbn2 & Mouse & Fbn2-/- & Iris coloboma & [137] \\
\hline Lamc1 \& Lamb1 & Zebrafish & Lamc1-/- & $\begin{array}{c}\text { Coloboma, disrupted retinal } \\
\text { lamination }\end{array}$ & [138] \\
\hline Efna5 & Mouse & Efna5-/- & Coloboma & [139] \\
\hline EphB2 & Mouse & $\begin{array}{c}\text { Dominant negative } \\
\text { transgene }\end{array}$ & Coloboma, microphthalmia & [139] \\
\hline Jag1 & Mouse & $\operatorname{Jag} 1+/ d D S L$ & Coloboma, corneal opacity & [193] \\
\hline hdac1 & Zebrafish & hdac-/- & Coloboma & [16] \\
\hline
\end{tabular}




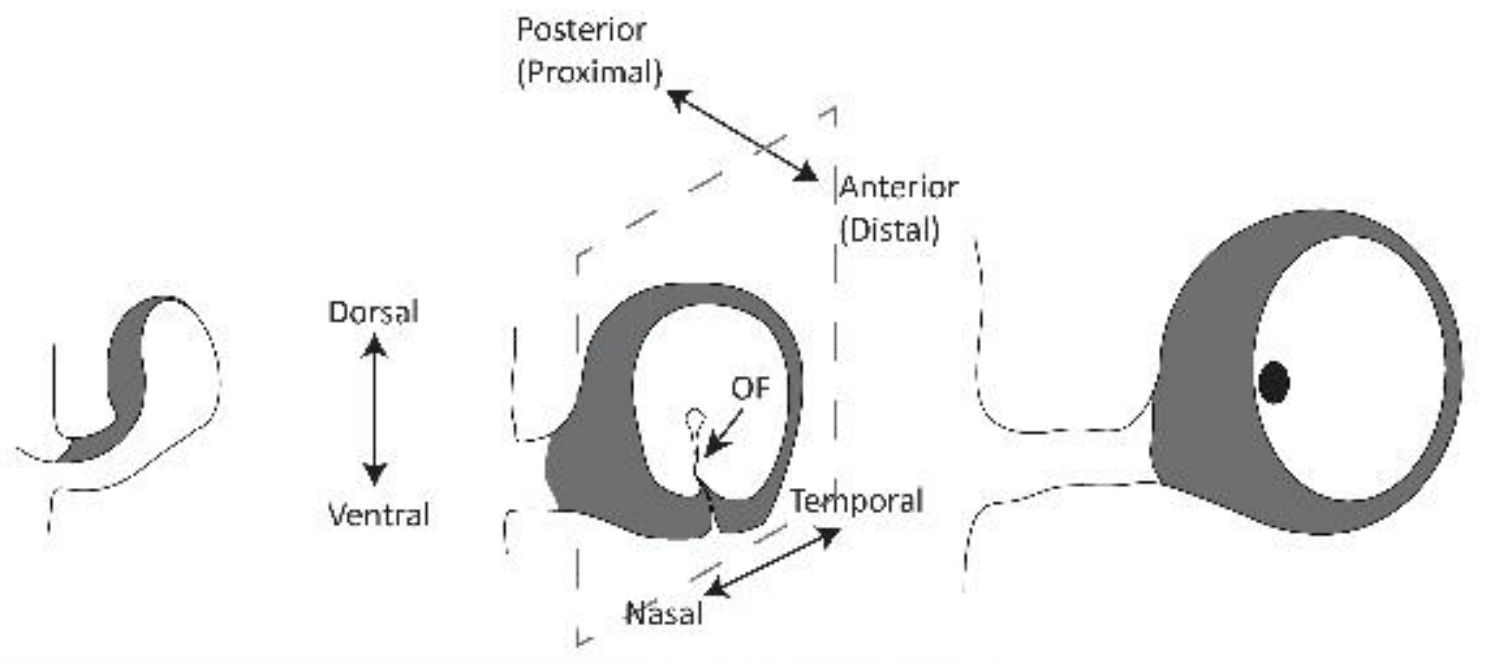

Axial Patterning of the optic vesicle and cup

Invagination and morphogenesis of the optic cup

Changes in cell morphology

Basement membrane dissolution and cell adhesion

Apoptosis
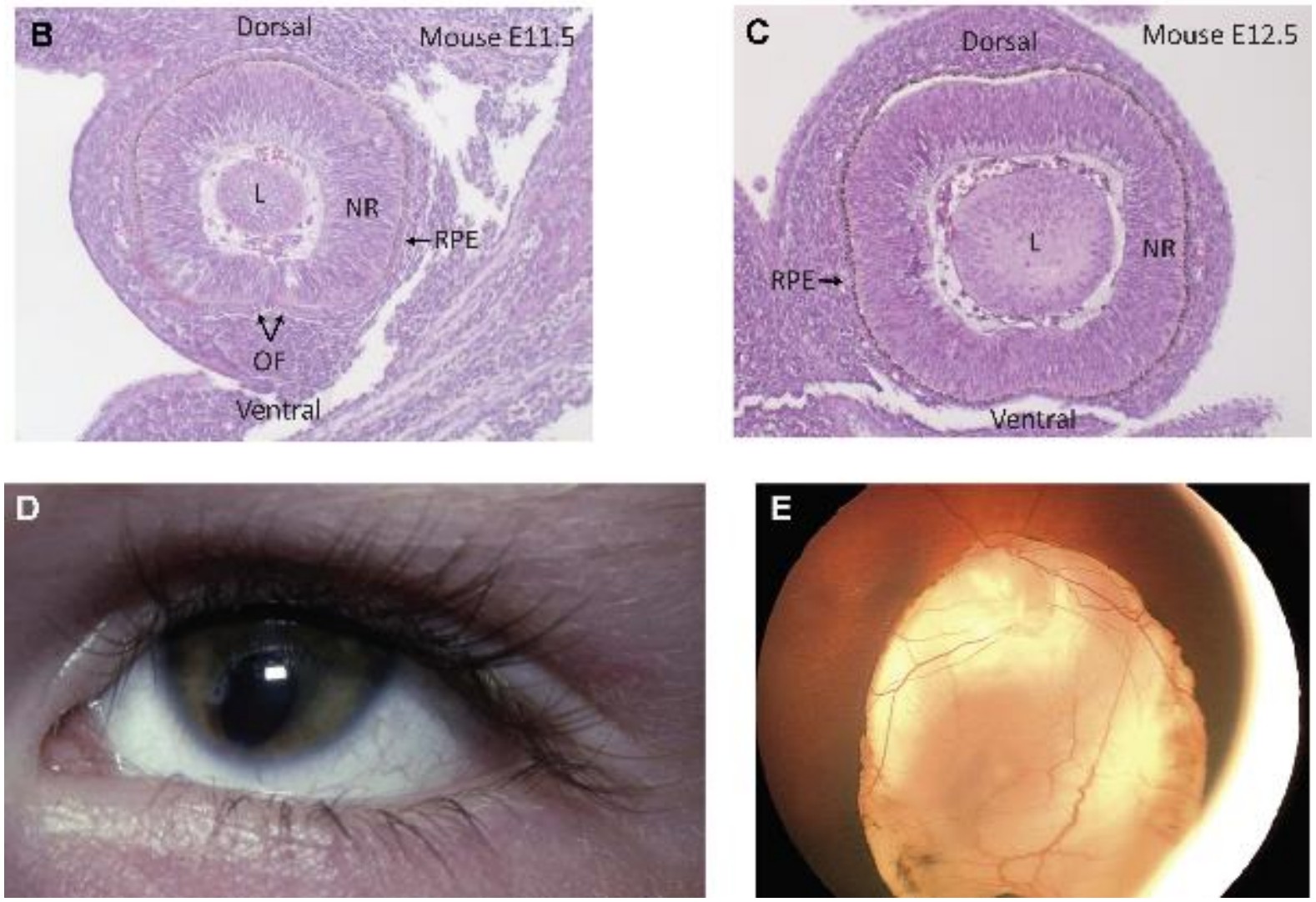

Figure 1: A: Processes involved in formation of the optic cup and closure of the optic cup. Shaded region of optic vesicle forms the outer layer of the optic cup. B: Histological section of developing 
mouse eye at E11.5 while the fissure is open. C: Histological section of developing mouse eye at E12.5 where the fissure is closed. D: Coloboma of anterior segment, E: Coloboma of posterior segment. NR: Neural Retina, RPE: Retinal Pigmented Epithelium, L: Lens OF: Optic Fissure. A: adapted from [140]. D and E reproduced with permission from [141].

\section{Alignment of fissure margins}

\subsection{Axial patterning of the optic vesicle and cup}

The early patterning of the optic vesicle and cup has been studied in detail and extensively reviewed $[142,143]$. However, it will be discussed in brief here as correct patterning along the proximal-distal, dorsal-ventral and nasal-temporal axes of the optic cup ensures that the margins of the optic fissure closely appose each other and enables the process of closure. Gradients of signalling molecules (Fig 2 A) collectively regulate the differential expression of key transcription factors including Pax2, Pax6, Vax1, Vax2, Tbx2, Tbx3,Tbx5, Vsx2 and Mitf in the optic vesicle and optic cup and Foxc1 and Pitx2 in the periocular mesenchyme (POM) [140, 144-148] (Fig 2 B).

The transcription factor gene Pax6 is expressed early in the eye field of the mouse embryo [145]. Along with Rax and $L h x 2$ it is one of the earliest determinants of the eye field [45, 149]. Sonic Hedgehog (Shh) signalling originating from the ventral midline of the developing forebrain inhibits Pax6 and divides the eye field, allowing the formation of two optic vesicles [100]. Pax2 is first expressed in the distal optic vesicle apposed to the surface ectoderm [144]. Shh signalling from the ventral midline and optic stalks then promotes proximal-distal and dorsal-ventral patterning of the optic cups by upregulating Pax2 expression in the optic stalk and optic fissure margins and restricting expression of Pax6 to the inner layer of the optic cup as invagination proceeds $[100,109,150]$. Pax2 and Pax6 mutually inhibit each other to establish a boundary between the RPE and optic nerve. Heterozygous mutations in human PAX2 [55], PAX6 [17], and SHH (1 family) [98] are known to cause coloboma. Additional factors mediating Shh signalling in the eye include Cdon and Ptch $[123,151]$. Shh also upregulates Vax1 which has an expression pattern similar to Pax2 [121].

Another major inducer of axial patterning, $B m p 4$, is expressed in the dorsal optic cup and induces the expression of the dorsal transcription factors $T b \times 5, T b \times 2$ and $T b \times 3$. These in turn restrict the expression of the ventral marker Vax2 to the optic fissure margins $[152,153]$. The expression of Bmp4 itself is restricted to the dorsal retina by Shh from the optic stalk and ventral midline [154]. The role of Bmp7, another Bmp family member is described in section 4.2. Both layers of the optic cup are initially bipotential. FGF signalling originating from the overlying lens placode promotes a neural fate in the inner layer by downregulating Mitf, allowing Vsx2 expression and establishing the boundary between the NR and RPE at the optic fissure margins $[148,155,156]$. Maintenance of $V s \times 2$ expression in the 
NR also depends on Bmp signalling [157]. Maintenance of the RPE fate in the outer layer requires Wnt$\beta$-catenin signalling $[129,130,158,159]$. A mutation in the WNT receptor gene FZD5 has been implicated in human patients with coloboma [41].

The final major signalling pathway involved in optic cup patterning is retinoic signalling [160]. It is described in section 4.2 as it appears to act via paracrine signalling to the POM [161]. In addition, the Hippo kinase signalling pathway induces RPE fate in the outer layer of the optic cup and has recently been shown to be essential for fissure closure [77, 79].

A

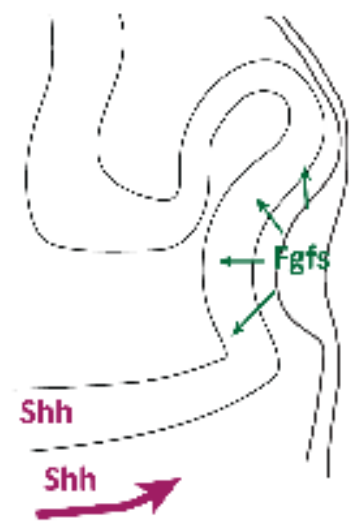

B

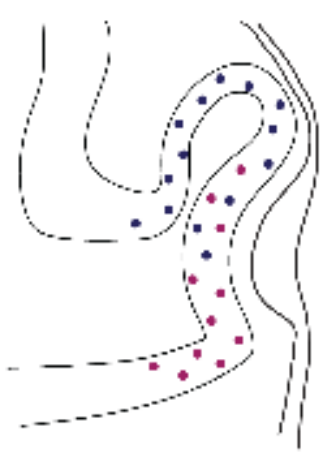

Posterior

(Proximal)

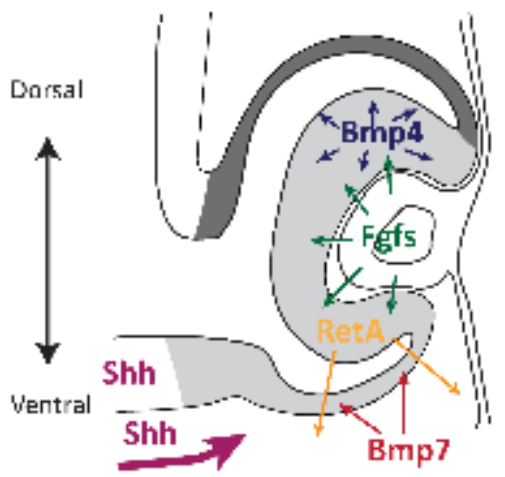

Posterior (Proximal')

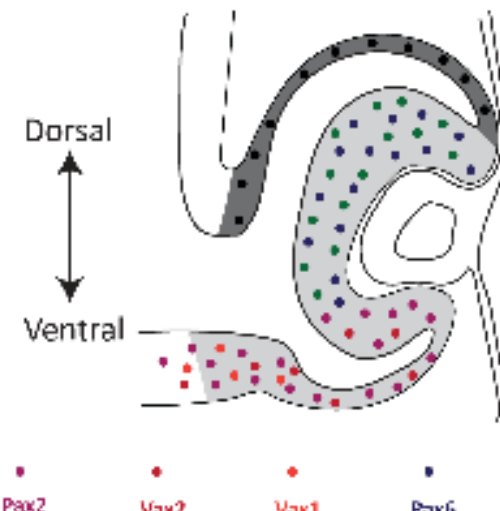

Nasal Terriporsl
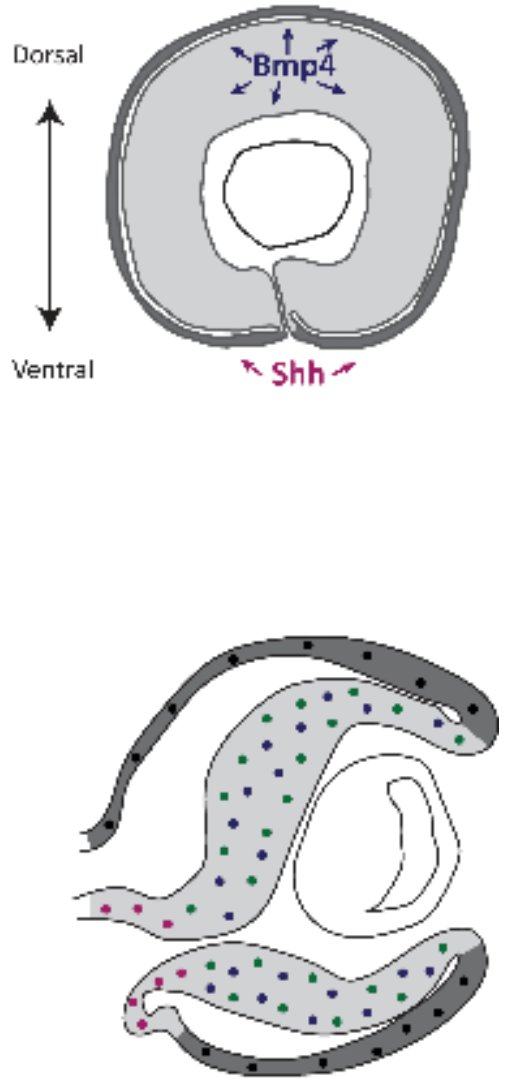

Fig. 2. A: Gradients of signalling molecules pattern the developing optic cup. NR: light gray, RPE: dark gray. The single pseudo stratified neuroepithelium of the optic vesicle folds to form the optic cup; the basal lamina faces the overlying surface ectoderm and the apical surface faces the lumen of the developing forebrain. B: Differential expression of key transcription factors in the optic cup.

\subsection{Invagination and morphogenesis of the optic cup}


Patterning of the optic vesicle is accompanied by a physical invagination to form the optic cup. The neuroepithelial cells of the single layered optic vesicle have an apically constricted shape. To form the double layered optic cup, the cells destined to form the inner layer must change to a basally constricted shape (Fig 3 A) [162]. This change depends on regulated contraction of the actin-myosin cytoskeleton $[163,164]$. Mutations in the human cytoplasmic actin genes ACTG1 and ACTB have been implicated in Baraitser-Winter syndrome which includes ocular coloboma [70, 165]. Studies in medaka fish have shown that basal constriction is achieved, at least partially, through the enrichment of focal adhesions at the basal ends of cells, and the resultant basolateral transmission of stress along the epithelial sheet. One of the factors promoting this basal enrichment is a transmembrane protein, encoded by the gene opo (ofcc1), which localizes to the basal end feet $[134,166]$. Transcription of opo is regulated by vsx2 [27], demonstrating a direct link between the patterning of the optic vesicle and physical morphogenesis of the bi-layered optic cup. Another important aspect of invagination, that acts in addition to basal constriction, is the migration of cells. Cell migration in response to fgf signalling was initially reported in relation to nasal-temporal patterning of the neural retina of zebrafish embryos [167]. Live imaging studies confirmed a flow of epithelial cells from the outer to the inner layer of the optic cup around the anterior rim and the fissure margins, which is also dependent on local inhibition of Bmp signalling $[168,169]$. There is also evidence from the developing Xenopus embryo suggesting that the margins of the optic fissure are lined by a population of cells that move distally from the optic stalk into the region of the fissure [170].

The inner layer also contains more proliferating cells than the outer layer [171]. Several studies, mainly in mouse embryos, indicate that correct invagination of the optic cup requires regulation of proliferation along the dorso-ventral axis $[125,172,173]$. However, experiments using zebrafish showed that proliferation may be dispensable and compensated for by other mechanisms [169, 174]. Finally, while the initial specification of the NR is influenced by signalling factors from the overlying lens placode $[148,155,156]$, it does not appear that the physical lens vesicle is required for invagination as stem cell-derived optic vesicles grown in-vitro do invaginate [163].

\section{Processes occurring at the fissure margins}

Current evidence indicates that optic fissure closure begins at the midpoint of the fissure and proceeds both distally and proximally [5, 175-177]. Prior to closure, the cells at the folding point between the two layers are oriented with their long axes almost perpendicular to the fissure, the basal ends facing the fissure (Fig $3 \mathrm{~A}-\mathrm{C}$ ) [178]. After closure they are reoriented in two continuous sheets with their apical surfaces facing each other (Fig 1C). 

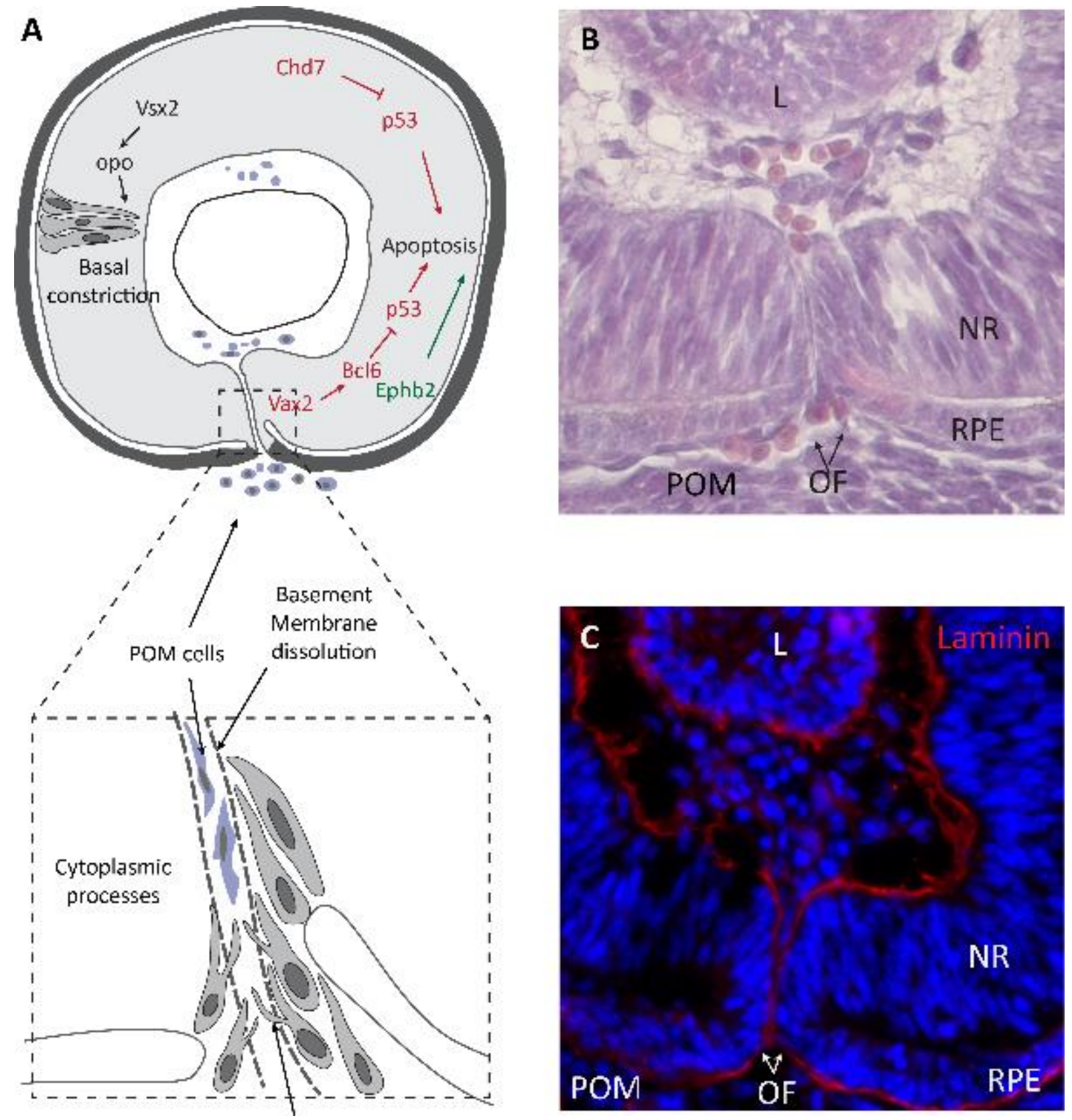

Figure 3: A: A schematic of the optic cup with pathways regulating basal constriction, apoptosis and changes in cell morphology at the fissure margins. B and C: Histological sections of a closing optic fissure in a mouse embryo. Laminin (red) labels the basement membrane. NR: Neural Retina, RPE: Retinal Pigmented Epithelium, L: Lens, OF: Optic Fissure, POM: Periocular Mesenchyme.

\subsection{Changes in cell morphology at the optic fissure}

The epithelial remodelling at the fissure requires extensive changes in cell shape and orientation, an aspect that has not been explored in great detail. Electron microscopy studies in mouse and hamster embryos have shown that as the margins of the optic fissure come in contact with each other the outer layer inverts into the margin (Fig 3 A; boxed region) and completes fusion first. Then the inner 
layer fuses and the become continuous sheets $[5,178,179]$. Also, the cells lining the margins appear to extend cytoplasmic processes from their basal surfaces (Fig 3 A) [5]. Recently, similar basal cell protrusions have been demonstrated in cells at the anterior rim of the optic cup in zebrafish [169]. Genes regulating these basal cell protrusions are not known. Cellular protrusions are also involved in neural tube closure [180], although these originate from the apical ends of cells.

\subsection{The role of the periocular mesenchyme}

The POM, which arises from neural crest and cranial mesodermal cells, transiently occupies the space between the optic fissure margins (Fig $3 \mathrm{~A}-\mathrm{C}$ ). The cells enter the optic cup through the fissure and give rise to the hyaloid vasculature that supplies the developing lens. This makes the POM a very likely source of secreted factors affecting fissure closure [181]. One of the key transcription factors expressed in the POM, and essential for its maintenance and function, is Pitx2. Pitx2 null mice were shown to have coloboma [131]. In zebrafish, knockdown of another key POM transcription factor, Imx1b, also caused a failure of fissure closure and a disorganized ventral retina [15]. Optic vesicles grown in-vitro without surrounding tissue do invaginate but symmetrically [163], further supporting the idea that the POM is essential for fissure formation. Mouse embryos lacking Bmp7 also show symmetrical invagination, reduced expression of the ventral marker Pax2, and failure to form an optic disc, optic nerve or hyaloid artery. The POM has been proposed as a likely source of Bmp7 affecting the ventral retina [182]. In the Imo2 mutant zebrafish, an abnormally inflated hyaloid vein causes reopening of the optic fissure even after closure has been initiated [132].

The survival and function of the POM is in turn regulated by retinoic acid secreted by the developing optic cup. Retinoic acid synthesizing enzymes are differentially expressed along the dorso-ventral axis. Retinoic acid promotes selective cell death in the periocular mesenchyme and prevents excessive invasion of the optic fissure by these cells [183]. Mouse embryos lacking retinoic acid synthesizing enzymes Aldh1a1 or Aldh1a3, or retinoic acid receptors Rarb and Rarg in the POM show ventral retinal defects with abnormal thickening of the POM and decreased expression of the POM specific transcription factors Pitx2 and Foxc1 [36, 161]. Modulating retinoic acid signalling in the developing zebrafish caused similar changes in gene expression in the POM and resulted in coloboma [184]. Mutations in the human serum retinol binding protein gene RBP4 cause eye defects including coloboma $[47,49,50]$.

\subsection{Basement Membrane dissolution and cell adhesion}


During closure the basement membranes lining the fissure margins initially become apposed to form a double basement membrane (Fig $3 \mathrm{D}$ ) and then disintegrate bringing the cell membranes in direct contact [5], although the mechanism is not entirely understood. Several models of ocular coloboma show a persistence of the basement membrane between the aligned fissure margins $[58,185,186]$. Early electron microscopy studies showed cells with a phagocytic appearance, probably originating from the POM, between the aligned margins of the fissure and it was suggested that they may contribute to basement membrane breakdown by releasing extracellular enzymes $[5,6]$. A recent study in zebrafish showed that disruption of talin1, an actin cytoskeleton regulator expressed in the POM prevented basement membrane breakdown at the fissure margins [177], supporting the hypothesis that these cells actively break down the basement membrane. As the basement membrane dissolves, the cells from the corresponding layers at either margin begin to form junctions between themselves, including Cadherin-mediated adherens junctions [135, 136], forming two continuous epithelial sheets.

\subsection{Apoptosis at the optic fissure}

There is increasing evidence to show that a precise control of apoptosis around the optic fissure is necessary for successful closure. Early studies detected the presence of apoptotic cells in the fissure margins of the developing mouse and human eyes $[5,187,188]$. More recent studies suggest that these are not just a by-product of the closure process and that both excessive and not enough apoptosis in the region of the optic fissure can cause closure defects.

Mutations in the human DNA helicase gene CHD7 cause CHARGE syndrome, which includes retinal coloboma as one of its characteristic features [60]. Heterozygous loss of Chd7 causes a similar phenotype in mice [189]. A recent study has shown that Chd7 acts, at least partially, by preventing inappropriate expression of the pro-apoptotic gene p53 and so controlling apoptosis in the developing eye and other organs affected in CHARGE syndrome [190]. This finding is supported by a study in zebrafish which showed that the anti-apoptotic factor bcl6 and its co-repressor bcor act downstream of the ventrally expressed transcription factor, vax 2 to supress p53 and reduce apoptosis, allowing successful fissure closure [109]. Apoptosis at the fissure may also be promoted by the interaction of ephrin-A5 with the receptor EphB2 at the margins of the optic fissure, especially in the proximal region of the optic cup. Both ephrin-A5 and EphB2 null mice showed optic fissure closure defects with reduced apoptosis and increased proliferation but without disrupting the expression of ventral patterning genes Pax2 and Vax2 [139].

\section{Open Questions}


Although several genes are now associated with human patients or animal models of coloboma, the functions of many of these remain unexplained. For example, biallelic mutations in SMOC1 cause microphthalmia or coloboma and limb anomalies in humans and mice [96, 97]. Smoc1 is a secreted basement membrane protein [191] and a study using cultured human cells has reported that it is involved in the adhesion of epithelial cells [192], which would be relevant to optic fissure closure. However, how it interacts with other eye development genes is not known. Many important new insights have been gained by study of zebrafish models but there is limited evidence of whether equivalent processes are important in the mammalian eye.

A large proportion of patients with coloboma have only one eye affected [7], most without a known genetic cause. Sometimes, they are part of families with multiple affected individuals. One can speculate that the mutations responsible for these defects are not completely penetrant, in that they do not have the same effect on both eyes even within the same individual, or alternatively that a single genetic mutation is not the sole cause. It may also be useful to investigate modes of inheritance other than simple Mendelian inheritance. A recent study has identified a maternal mode of transmission for mutations in RBP4 resulting in MAC with reduced penetrance [48].

\section{Conclusion}

The early patterning of the optic vesicle and cup are now quite well understood. The majority of coloboma disease genes identified so far are have been components of signalling pathways and transcription factors involved in general pattering of the optic cup and regulating cell proliferation and death. Much less is known about the morphological changes that occur at the margins and enable epithelium remodelling or the genes that control them. Some recent studies have attempted to address this using live imaging in zebrafish. While it remains to be shown that these remodelling processes are conserved in mammals, the genes involved can be investigated as potential coloboma disease genes. 


\section{Acknowledgements}

This work is supported by the Rosetrees Trust and National Institute for Health Research Biomedical Research Centre at Great Ormond Street Hospital for Children NHS Foundation Trust and University College London. AP is funded by the UCL Graduate Research and Overseas Research Scholarships, J.C.S. is funded by the Great Ormond Street Hospital Children's Charity.

1. Kaufman, M.H., The atlas of mouse development. 1992: Academic.

2. O'Rahilly, R., The timing and sequence of events in the development of the human eye and ear during the embryonic period proper. Anat Embryol (Berl), 1983. 168(1): p. 87-99.

3. Schmitt, E.A. and J.E. Dowling, Early eye morphogenesis in the zebrafish, Brachydanio rerio. J Comp Neurol, 1994. 344(4): p. 532-42.

4. O'Rahilly, R. and F. Muller, Developmental stages in human embryos : including a revision of Streeter's "Horizons" and a survey of the Carnegie Collection. 1987, Washington, D.C.: Carnegie Institution of Washington.

5. Hero, I., Optic fissure closure in the normal cinnamon mouse. An ultrastructural study. Invest Ophthalmol Vis Sci, 1990. 31(1): p. 197-216.

6. Hero, I., M. Farjah, and C.L. Scholtz, The prenatal development of the optic fissure in colobomatous microphthalmia. Invest Ophthalmol Vis Sci, 1991. 32(9): p. 2622-35.

7. Morrison, D., et al., National study of microphthalmia, anophthalmia, and coloboma (MAC) in Scotland: investigation of genetic aetiology. J Med Genet, 2002. 39(1): p. 16-22.

8. Onwochei, B.C., et al., Ocular colobomata. Surv Ophthalmol, 2000. 45(3): p. 175-94.

9. Hornby, S.J., et al., Environmental risk factors in congenital malformations of the eye. Ann Trop Paediatr, 2002. 22(1): p. 67-77.

10. Rahi, J.S., et al., Childhood blindness in India: causes in 1318 blind school students in nine states. Eye (Lond), 1995. 9 ( Pt 5): p. 545-50.

11. Gregory-Evans, C.Y., et al., SNP genome scanning localizes oto-dental syndrome to chromosome 11q13 and microdeletions at this locus implicate FGF3 in dental and inner-ear disease and FADD in ocular coloboma. Hum Mol Genet, 2007. 16(20): p. 2482-93.

12. Adly, N., et al., Ciliary genes TBC1D32/C6orf170 and SCLT1 are mutated in patients with OFD type IX. Hum Mutat, 2014. 35(1): p. 36-40.

13. Chao, R., et al., A male with unilateral microphthalmia reveals a role for TMX3 in eye development. PLoS One, 2010. 5(5): p. e10565.

14. Brown, J.D., et al., Expression profiling during ocular development identifies $2 \mathrm{Nlz}$ genes with a critical role in optic fissure closure. Proc Natl Acad Sci U S A, 2009. 106(5): p. 1462-7.

15. McMahon, C., et al., $L m \times 1 b$ is essential for survival of periocular mesenchymal cells and influences Fgf-mediated retinal patterning in zebrafish. Dev Biol, 2009. 332(2): p. 287-98.

16. Lee, J., B.K. Lee, and J.M. Gross, Bcl6a function is required during optic cup formation to prevent p53-dependent apoptosis and colobomata. Hum Mol Genet, 2013. 22(17): p. 356882.

17. Azuma, N., et al., Mutations of the PAX6 gene detected in patients with a variety of opticnerve malformations. Am J Hum Genet, 2003. 72(6): p. 1565-70.

18. Deml, B., et al., Novel mutations in PAX6, OTX2 and NDP in anophthalmia, microphthalmia and coloboma. Eur J Hum Genet, 2016. 24(4): p. 535-41.

19. Hill, R.E., et al., Mouse small eye results from mutations in a paired-like homeoboxcontaining gene. Nature, 1991. 354(6354): p. 522-5. 
20. Ferda Percin, E., et al., Human microphthalmia associated with mutations in the retinal homeobox gene CHX10. Nat Genet, 2000. 25(4): p. 397-401.

21. Bar-Yosef, U., et al., CHX10 mutations cause non-syndromic microphthalmia/ anophthalmia in Arab and Jewish kindreds. Hum Genet, 2004. 115(4): p. 302-9.

22. Burkitt Wright, E.M., et al., VSX2 in microphthalmia: a novel splice site mutation producing a severe microphthalmia phenotype. Br J Ophthalmol, 2010. 94(3): p. 386-8.

23. Iseri, S.U., et al., Use of genome-wide SNP homozygosity mapping in small pedigrees to identify new mutations in VSX2 causing recessive microphthalmia and a semidominant inner retinal dystrophy. Hum Genet, 2010. 128(1): p. 51-60.

24. Chassaing, N., et al., Molecular findings and clinical data in a cohort of 150 patients with anophthalmia/microphthalmia. Clin Genet, 2014. 86(4): p. 326-34.

25. Burmeister, M., et al., Ocular retardation mouse caused by Chx10 homeobox null allele: impaired retinal progenitor proliferation and bipolar cell differentiation. Nat Genet, 1996. 12(4): p. 376-84.

26. Zou, C. and E.M. Levine, Vsx2 controls eye organogenesis and retinal progenitor identity via homeodomain and non-homeodomain residues required for high affinity DNA binding. PLoS Genet, 2012. 8(9): p. e1002924.

27. Gago-Rodrigues, I., et al., Analysis of opo cis-regulatory landscape uncovers Vsx2 requirement in early eye morphogenesis. Nat Commun, 2015. 6: p. 7054.

28. Jamieson, R.V., et al., Pulverulent cataract with variably associated microcornea and iris coloboma in a MAF mutation family. Br J Ophthalmol, 2003. 87(4): p. 411-2.

29. Jamieson, R.V., et al., Domain disruption and mutation of the bZIP transcription factor, MAF, associated with cataract, ocular anterior segment dysgenesis and coloboma. Hum Mol Genet, 2002. 11(1): p. 33-42.

30. Hansen, L., H. Eiberg, and T. Rosenberg, Novel MAF mutation in a family with congenital cataract-microcornea syndrome. Mol Vis, 2007. 13: p. 2019-22.

31. Narumi, Y., et al., Identification of a novel missense mutation of MAF in a Japanese family with congenital cataract by whole exome sequencing: a clinical report and review of literature. Am J Med Genet A, 2014. 164A(5): p. 1272-6.

32. Kawauchi, S., et al., Regulation of lens fiber cell differentiation by transcription factor c-Maf. J Biol Chem, 1999. 274(27): p. 19254-60.

33. Yahyavi, M., et al., ALDH1A3 loss of function causes bilateral anophthalmia/microphthalmia and hypoplasia of the optic nerve and optic chiasm. Hum Mol Genet, 2013. 22(16): p. 3250-8.

34. Fares-Taie, L., et al., ALDH1A3 mutations cause recessive anophthalmia and microphthalmia. Am J Hum Genet, 2013. 92(2): p. 265-70.

35. Roos, L., et al., A homozygous mutation in a consanguineous family consolidates the role of ALDH1A3 in autosomal recessive microphthalmia. Clin Genet, 2014. 86(3): p. 276-81.

36. Dupe, V., et al., A newborn lethal defect due to inactivation of retinaldehyde dehydrogenase type 3 is prevented by maternal retinoic acid treatment. Proc Natl Acad Sci U S A, 2003. 100(24): p. 14036-41.

37. Aldahmesh, M.A., et al., Homozygous null mutation in ODZ3 causes microphthalmia in humans. Genet Med, 2012. 14(11): p. 900-4.

38. Chassaing, N., et al., Confirmation of TENM3 involvement in autosomal recessive colobomatous microphthalmia. Am J Med Genet A, 2016. 170(7): p. 1895-8.

39. Wang, L., et al., ABCB6 mutations cause ocular coloboma. Am J Hum Genet, 2012. 90(1): p. 40-8.

40. Liu, C. and J. Nathans, An essential role for frizzled 5 in mammalian ocular development. Development, 2008. 135(21): p. 3567-76.

41. Liu, C., et al., A secreted WNT-ligand-binding domain of FZD5 generated by a frameshift mutation causes autosomal dominant coloboma. Hum Mol Genet, 2016. 25(7): p. 1382-91. 
42. Kelberman, D., et al., Mutation of SALL2 causes recessive ocular coloboma in humans and mice. Human Molecular Genetics, 2014. 23(10): p. 2511-2526.

43. Voronina, V.A., et al., Mutations in the human RAX homeobox gene in a patient with anophthalmia and sclerocornea. Hum Mol Genet, 2004. 13(3): p. 315-22.

44. London, N.J., et al., Sequence alterations in RX in patients with microphthalmia, anophthalmia, and coloboma. Mol Vis, 2009. 15: p. 162-7.

45. Mathers, P.H., et al., The Rx homeobox gene is essential for vertebrate eye development. Nature, 1997. 387(6633): p. 603-7.

46. Beby, F., et al., New phenotype associated with an Arg116Cys mutation in the CRYAA gene: nuclear cataract, iris coloboma, and microphthalmia. Arch Ophthalmol, 2007. 125(2): p. 2136.

47. Seeliger, M.W., et al., Phenotype in retinol deficiency due to a hereditary defect in retinol binding protein synthesis. Invest Ophthalmol Vis Sci, 1999. 40(1): p. 3-11.

48. Chou, C.M., et al., Biochemical Basis for Dominant Inheritance, Variable Penetrance, and Maternal Effects in RBP4 Congenital Eye Disease. Cell, 2015. 161(3): p. 634-46.

49. Cukras, C., et al., Exome analysis identified a novel mutation in the RBP4 gene in a consanguineous pedigree with retinal dystrophy and developmental abnormalities. PLoS One, 2012. 7(11): p. e50205.

50. Khan, K.N., et al., Vitamin A deficiency due to bi-allelic mutation of RBP4: There's more to it than meets the eye. Ophthalmic Genet, 2016: p. 1-2.

51. Ragge, N.K., et al., Heterozygous mutations of OTX2 cause severe ocular malformations. Am J Hum Genet, 2005. 76(6): p. 1008-22.

52. Wyatt, A., et al., Novel heterozygous OTX2 mutations and whole gene deletions in anophthalmia, microphthalmia and coloboma. Hum Mutat, 2008. 29(11): p. E278-83.

53. Ye, M., et al., Mutation of the bone morphogenetic protein GDF3 causes ocular and skeletal anomalies. Hum Mol Genet, 2010. 19(2): p. 287-98.

54. Prokudin, I., et al., Exome sequencing in developmental eye disease leads to identification of causal variants in GJA8, CRYGC, PAX6 and CYP1B1. Eur J Hum Genet, 2013.

55. Sanyanusin, P., et al., Mutation of the PAX2 gene in a family with optic nerve colobomas, renal anomalies and vesicoureteral reflux. Nat Genet, 1995. 9(4): p. 358-64.

56. Amiel, J., et al., PAX2 mutations in renal-coloboma syndrome: mutational hotspot and germline mosaicism. Eur J Hum Genet, 2000. 8(11): p. 820-6.

57. Chung, G.W., et al., Renal-coloboma syndrome: report of a novel PAX2 gene mutation. Am J Ophthalmol, 2001. 132(6): p. 910-4.

58. Torres, M., E. Gomez-Pardo, and P. Gruss, Pax2 contributes to inner ear patterning and optic nerve trajectory. Development, 1996. 122(11): p. 3381-91.

59. Schwarz, M., et al., Spatial specification of mammalian eye territories by reciprocal transcriptional repression of Pax2 and Pax6. Development, 2000. 127(20): p. 4325-34.

60. Vissers, L.E., et al., Mutations in a new member of the chromodomain gene family cause CHARGE syndrome. Nat Genet, 2004. 36(9): p. 955-7.

61. Lalani, S.R., et al., Spectrum of CHD7 mutations in 110 individuals with CHARGE syndrome and genotype-phenotype correlation. Am J Hum Genet, 2006. 78(2): p. 303-14.

62. Hurd, E.A., et al., Loss of Chd7 function in gene-trapped reporter mice is embryonic lethal and associated with severe defects in multiple developing tissues. Mamm Genome, 2007. 18(2): p. 94-104.

63. Aliferis, K., et al., A novel TFAP2A mutation in familial Branchio-Oculo-Facial Syndrome with predominant ocular phenotype. Ophthalmic Genet, 2011. 32(4): p. 250-5.

64. Dumitrescu, A.V., et al., A family with branchio-oculo-facial syndrome with primarily ocular involvement associated with mutation of the TFAP2A gene. Ophthalmic Genet, 2012. 33(2): p. 100-6. 
65. Gestri, G., et al., Reduced TFAP2A function causes variable optic fissure closure and retinal defects and sensitizes eye development to mutations in other morphogenetic regulators. Hum Genet, 2009. 126(6): p. 791-803.

66. Al-Dosari, M.S., et al., Ocular manifestations of branchio-oculo-facial syndrome: report of a novel mutation and review of the literature. Mol Vis, 2010. 16: p. 813-8.

67. Milunsky, J.M., et al., Genotype-phenotype analysis of the branchio-oculo-facial syndrome. Am J Med Genet A, 2011. 155A(1): p. 22-32.

68. Bassett, E.A., et al., AP-2alpha knockout mice exhibit optic cup patterning defects and failure of optic stalk morphogenesis. Hum Mol Genet, 2010. 19(9): p. 1791-804.

69. Ng, B.G., et al., Mutations in the glycosylphosphatidylinositol gene PIGL cause CHIME syndrome. Am J Hum Genet, 2012. 90(4): p. 685-8.

70. Riviere, J.B., et al., De novo mutations in the actin genes ACTB and ACTG1 cause BaraitserWinter syndrome. Nat Genet, 2012. 44(4): p. 440-4, S1-2.

71. Rainger, J., et al., Monoallelic and biallelic mutations in MAB21L2 cause a spectrum of major eye malformations. Am J Hum Genet, 2014. 94(6): p. 915-23.

72. Deml, B., et al., Mutations in MAB21L2 result in ocular Coloboma, microcornea and cataracts. PLoS Genet, 2015. 11(2): p. e1005002.

73. Yamada, R., et al., Requirement for Mab21/2 during development of murine retina and ventral body wall. Dev Biol, 2004. 274(2): p. 295-307.

74. Bourchany, A., et al., Clinical spectrum of eye malformations in four patients with MowatWilson syndrome. Am J Med Genet A, 2015. 167(7): p. 1587-92.

75. Wenger, T.L., et al., CHARGE-like presentation, craniosynostosis and mild Mowat-Wilson Syndrome diagnosed by recognition of the distinctive facial gestalt in a cohort of 28 new cases. Am J Med Genet A, 2014. 164A(10): p. 2557-66.

76. Gregory-Evans, C.Y., et al., Ocular coloboma and high myopia with Hirschsprung disease associated with a novel ZFHX1B missense mutation and trisomy 21. Am J Med Genet A, 2004. 131(1): p. 86-90.

77. Williamson, Kathleen A., et al., Heterozygous Loss-of-Function Mutations in YAP1 Cause Both Isolated and Syndromic Optic Fissure Closure Defects. The American Journal of Human Genetics, 2014. 94(2): p. 295-302.

78. Oatts, J.T., et al., Novel heterozygous mutation in YAP1 in a family with isolated ocular colobomas. Ophthalmic Genet, 2016: p. 1-3.

79. Miesfeld, J.B., et al., Yap and Taz regulate retinal pigment epithelial cell fate. Development, 2015. 142(17): p. 3021-32.

80. Wang, P., et al., Novel SOX2 mutation associated with ocular coloboma in a Chinese family. Arch Ophthalmol, 2008. 126(5): p. 709-13.

81. Ragge, N.K., et al., SOX2 anophthalmia syndrome. Am J Med Genet A, 2005. 135(1): p. 1-7; discussion 8.

82. Stark, Z., et al., Isolated hypogonadotropic hypogonadism with SOX2 mutation and anophthalmia/microphthalmia in offspring. European Journal of Human Genetics, 2011. 19(7): p. 753-756.

83. Bakrania, P., et al., SOX2 anophthalmia syndrome: 12 new cases demonstrating broader phenotype and high frequency of large gene deletions. Br J Ophthalmol, 2007. 91(11): $\mathrm{p}$. 1471-6.

84. Langer, L., et al., SOX2 hypomorphism disrupts development of the prechordal floor and optic cup. Mech Dev, 2012. 129(1-4): p. 1-12.

85. Schorderet, D.F., et al., Mutation in the human homeobox gene NKX5-3 causes an oculoauricular syndrome. Am J Hum Genet, 2008. 82(5): p. 1178-84.

86. Gillespie, R.L., et al., Abrogation of HMX1 function causes rare oculoauricular syndrome associated with congenital cataract, anterior segment dysgenesis, and retinal dystrophy. Invest Ophthalmol Vis Sci, 2015. 56(2): p. 883-91. 
87. Munroe, R.J., et al., Mouse H6 Homeobox 1 (Hmx1) mutations cause cranial abnormalities and reduced body mass. BMC Dev Biol, 2009. 9: p. 27.

88. Horn, D., et al., Novel mutations in BCOR in three patients with oculo-facio-cardio-dental syndrome, but none in Lenz microphthalmia syndrome. Eur J Hum Genet, 2005. 13(5): p. 5639.

89. Hilton, E., et al., BCOR analysis in patients with OFCD and Lenz microphthalmia syndromes, mental retardation with ocular anomalies, and cardiac laterality defects. Eur J Hum Genet, 2009. 17(10): p. 1325-35.

90. $\mathrm{Ng}$, D., et al., Oculofaciocardiodental and Lenz microphthalmia syndromes result from distinct classes of mutations in BCOR. Nat Genet, 2004. 36(4): p. 411-6.

91. George, A., et al., Biallelic Mutations in MITF Cause Coloboma, Osteopetrosis, Microphthalmia, Macrocephaly, Albinism, and Deafness. Am J Hum Genet, 2016. 99(6): p. 1388-1394.

92. Hodgkinson, C.A., et al., Mutations at the mouse microphthalmia locus are associated with defects in a gene encoding a novel basic-helix-loop-helix-zipper protein. Cell, 1993. 74(2): p. 395-404.

93. Zahrani, F., et al., Mutations in c12orf57 cause a syndromic form of colobomatous microphthalmia. Am J Hum Genet, 2013. 92(3): p. 387-91.

94. Salih, M.A., et al., A newly recognized autosomal recessive syndrome affecting neurologic function and vision. Am J Med Genet A, 2013. 161A(6): p. 1207-13.

95. Platzer, K., et al., Exome sequencing identifies compound heterozygous mutations in C12orf57 in two siblings with severe intellectual disability, hypoplasia of the corpus callosum, chorioretinal coloboma, and intractable seizures. Am J Med Genet A, 2014. 164A(8): p. 197680.

96. Rainger, J., et al., Loss of the BMP antagonist, SMOC-1, causes Ophthalmo-acromelic (Waardenburg Anophthalmia) syndrome in humans and mice. PLoS Genet, 2011. 7(7): p. e1002114.

97. Okada, I., et al., SMOC1 is essential for ocular and limb development in humans and mice. Am J Hum Genet, 2011. 88(1): p. 30-41.

98. Schimmenti, L.A., et al., Novel mutation in sonic hedgehog in non-syndromic colobomatous microphthalmia. Am J Med Genet A, 2003. 116A(3): p. 215-21.

99. Bakrania, P., et al., Sonic hedgehog mutations are an uncommon cause of developmental eye anomalies. Am J Med Genet A, 2010. 152A(5): p. 1310-3.

100. Chiang, C., et al., Cyclopia and defective axial patterning in mice lacking Sonic hedgehog gene function. Nature, 1996. 383(6599): p. 407-13.

101. Macdonald, R. and S.W. Wilson, Pax proteins and eye development. Curr Opin Neurobiol, 1996. 6(1): p. 49-56.

102. Asai-Coakwell, M., et al., GDF6, a novel locus for a spectrum of ocular developmental anomalies. Am J Hum Genet, 2007. 80(2): p. 306-15.

103. Asai-Coakwell, M., et al., Incomplete penetrance and phenotypic variability characterize Gdf6-attributable oculo-skeletal phenotypes. Hum Mol Genet, 2009. 18(6): p. 1110-21.

104. French, C.R., et al., Apoptotic and proliferative defects characterize ocular development in a microphthalmic BMP model. Invest Ophthalmol Vis Sci, 2013. 54(7): p. 4636-47.

105. Lalani, S.R., et al., SEMA3E mutation in a patient with CHARGE syndrome. J Med Genet, 2004. 41(7): p. e94.

106. Wallis, D.E., et al., Mutations in the homeodomain of the human SIX3 gene cause holoprosencephaly. Nat Genet, 1999. 22(2): p. 196-8.

107. Lacbawan, F., et al., Clinical spectrum of SIX3-associated mutations in holoprosencephaly: correlation between genotype, phenotype and function. Journal of Medical Genetics, 2009. 46(6): p. 389-398. 
108. Ribeiro, L.A., J.C. Murray, and A. Richieri-Costa, PTCH mutations in four Brazilian patients with holoprosencephaly and in one with holoprosencephaly-like features and normal MRI. Am J Med Genet A, 2006. 140(23): p. 2584-6.

109. Lee, J., et al., Zebrafish blowout provides genetic evidence for Patched1-mediated negative regulation of Hedgehog signaling within the proximal optic vesicle of the vertebrate eye. Dev Biol, 2008. 319(1): p. 10-22.

110. Kahrizi, K., et al., Next generation sequencing in a family with autosomal recessive Kahrizi syndrome (OMIM 612713) reveals a homozygous frameshift mutation in SRD5A3. Eur J Hum Genet, 2011. 19(1): p. 115-7.

111. Martinez-Garay, I., et al., A two base pair deletion in the PQBP1 gene is associated with microphthalmia, microcephaly, and mental retardation. Eur J Hum Genet, 2007. 15(1): p. 2934.

112. Graham, J.M., Jr., et al., A new X-linked syndrome with agenesis of the corpus callosum, mental retardation, coloboma, micrognathia, and a mutation in the Alpha 4 gene at Xq13. Am J Med Genet A, 2003. 123A(1): p. 37-44.

113. Wyatt, A.W., et al., Bone morphogenetic protein 7 (BMP7) mutations are associated with variable ocular, brain, ear, palate, and skeletal anomalies. Hum Mutat, 2010. 31(7): p. 781-7.

114. Dudley, A.T., K.M. Lyons, and E.J. Robertson, A requirement for bone morphogenetic protein7 during development of the mammalian kidney and eye. Genes \& Development, 1995. 9(22): p. 2795-2807.

115. Scott, A.F., et al., Identification of an HMGB3 Frameshift Mutation in a Family With an Xlinked Colobomatous Microphthalmia Syndrome Using Whole-Genome and X-Exome Sequencing. JAMA Ophthalmol, 2014.

116. Thomas, S., et al., A homozygous PDE6D mutation in Joubert syndrome impairs targeting of farnesylated INPP5E protein to the primary cilium. Hum Mutat, 2014. 35(1): p. 137-46.

117. Botzenhart, E.M., et al., SALL1 mutation analysis in Townes-Brocks syndrome: twelve novel mutations and expansion of the phenotype. Hum Mutat, 2005. 26(3): p. 282.

118. Kiefer, S.M., et al., SALL1 truncated protein expression in Townes-Brocks syndrome leads to ectopic expression of downstream genes. Hum Mutat, 2008. 29(9): p. 1133-40.

119. Plaisancie, J., et al., MSX2 Gene Duplication in a Patient with Eye Development Defects. Ophthalmic Genet, 2015. 36(4): p. 353-8.

120. Wu, L.Y., et al., Microphthalmia resulting from MSX2-induced apoptosis in the optic vesicle. Invest Ophthalmol Vis Sci, 2003. 44(6): p. 2404-12.

121. Hallonet, M., et al., Vax1, a novel homeobox-containing gene, directs development of the basal forebrain and visual system. Genes Dev, 1999. 13(23): p. 3106-14.

122. Barbieri, A.M., et al., Vax2 inactivation in mouse determines alteration of the eye dorsalventral axis, misrouting of the optic fibres and eye coloboma. Development, 2002. 129(3): p. 805-13.

123. Zhang, W., et al., Ocular abnormalities in mice lacking the immunoglobulin superfamily member Cdo. FEBS J, 2009. 276(20): p. 5998-6010.

124. Lieven, O. and U. Ruther, The Dkk1 dose is critical for eye development. Dev Biol, 2011. 355(1): p. 124-37.

125. Behesti, H., V.E. Papaioannou, and J.C. Sowden, Loss of Tbx2 delays optic vesicle invagination leading to small optic cups. Dev Biol, 2009. 333(2): p. 360-72.

126. Huh, S., et al., Dorsal-ventral patterning defects in the eye of BF-1-deficient mice associated with a restricted loss of shh expression. Dev Biol, 1999. 211(1): p. 53-63.

127. Smith, R., et al., The Transcription Factor Foxg1 Promotes Optic Fissure Closure in the Mouse by Suppressing Wnt8b in the Nasal Optic Stalk. J Neurosci, 2017. 37(33): p. 7975-7993.

128. Tang, K., et al., COUP-TFs regulate eye development by controlling factors essential for optic vesicle morphogenesis. Development, 2010. 137(5): p. 725-34. 
129. Zhou, C.-J., et al., Ocular coloboma and dorsoventral neuroretinal patterning defects in Lrp6 mutant eyes. Developmental Dynamics, 2008. 237(12): p. 3681-3689.

130. Alldredge, A. and S. Fuhrmann, Loss of Axin2 Causes Ocular Defects During Mouse Eye Development. Invest Ophthalmol Vis Sci, 2016. 57(13): p. 5253-5262.

131. Gage, P.J., H. Suh, and S.A. Camper, Dosage requirement of Pitx2 for development of multiple organs. Development, 1999. 126(20): p. 4643-51.

132. Weiss, O., et al., Abnormal vasculature interferes with optic fissure closure in Imo2 mutant zebrafish embryos. Dev Biol, 2012. 369(2): p. 191-8.

133. Zhang, R., et al., Sma- and Mad-related protein 7 (Smad7) is required for embryonic eye development in the mouse. J Biol Chem, 2013. 288(15): p. 10275-85.

134. Martinez-Morales, J.R., et al., ojoplano-mediated basal constriction is essential for optic cup morphogenesis. Development, 2009. 136(13): p. 2165-75.

135. Chen, S., et al., Cadherin-mediated cell adhesion is critical for the closing of the mouse optic fissure. PLoS One, 2012. 7(12): p. e51705.

136. Masai, I., et al., $\mathrm{N}$-cadherin mediates retinal lamination, maintenance of forebrain compartments and patterning of retinal neurites. Development, 2003. 130(11): p. 2479-94.

137. Shi, Y., et al., Ocular phenotype of Fbn2-null mice. Invest Ophthalmol Vis Sci, 2013. 54(12): p. 7163-73.

138. Lee, J. and J.M. Gross, Laminin beta1 and gamma1 containing laminins are essential for basement membrane integrity in the zebrafish eye. Invest Ophthalmol Vis Sci, 2007. 48(6): p. 2483-90.

139. Noh, H., et al., Proper closure of the optic fissure requires ephrin A5-EphB2-JNK signaling. Development, 2016. 143(3): p. 461-72.

140. Mui, S.H., et al., Vax genes ventralize the embryonic eye. Genes Dev, 2005. 19(10): p. 124959.

141. Hoyt, C.S. and D. Taylor, Practical pediatric ophthalmology and strabismus. 2013, Edinburgh: Elsevier Health Sciences UK. 1 online resource (1229 pages).

142. Fuhrmann, S., Eye morphogenesis and patterning of the optic vesicle. Curr Top Dev Biol, 2010. 93: p. 61-84.

143. Reis, L.M. and E.V. Semina, Conserved genetic pathways associated with microphthalmia, anophthalmia, and coloboma. Birth Defects Res C Embryo Today, 2015.

144. Nornes, H.O., et al., Spatially and temporally restricted expression of Pax2 during murine neurogenesis. Development, 1990. 109(4): p. 797-809.

145. Walther, C. and P. Gruss, Pax-6, a murine paired box gene, is expressed in the developing CNS. Development, 1991. 113(4): p. 1435-49.

146. Hallonet, M., et al., Vax1 is a novel homeobox-containing gene expressed in the developing anterior ventral forebrain. Development, 1998. 125(14): p. 2599-610.

147. Barbieri, A.M., et al., A homeobox gene, vax2, controls the patterning of the eye dorsoventral axis. Proc Natl Acad Sci U S A, 1999. 96(19): p. 10729-34.

148. Nguyen, M. and H. Arnheiter, Signaling and transcriptional regulation in early mammalian eye development: a link between FGF and MITF. Development, 2000. 127(16): p. 3581-91.

149. Roy, A., et al., LHX2 is necessary for the maintenance of optic identity and for the progression of optic morphogenesis. J Neurosci, 2013. 33(16): p. 6877-84.

150. Macdonald, R., et al., Midline signalling is required for Pax gene regulation and patterning of the eyes. Development, 1995. 121(10): p. 3267-78.

151. Cardozo, M.J., et al., Cdon acts as a Hedgehog decoy receptor during proximal-distal patterning of the optic vesicle. Nat Commun, 2014. 5: p. 4272.

152. Behesti, H., J.K. Holt, and J.C. Sowden, The level of BMP4 signaling is critical for the regulation of distinct T-box gene expression domains and growth along the dorso-ventral axis of the optic cup. BMC Dev Biol, 2006. 6: p. 62. 
153. Furuta, Y. and B.L. Hogan, BMP4 is essential for lens induction in the mouse embryo. Genes Dev, 1998. 12(23): p. 3764-75.

154. Zhao, L., et al., Sonic hedgehog is involved in formation of the ventral optic cup by limiting Bmp4 expression to the dorsal domain. Mech Dev, 2010. 127(1-2): p. 62-72.

155. Cai, Z., et al., Deficient FGF signaling causes optic nerve dysgenesis and ocular coloboma. Development, 2013. 140(13): p. 2711-23.

156. Cai, Z., G.S. Feng, and X. Zhang, Temporal requirement of the protein tyrosine phosphatase Shp2 in establishing the neuronal fate in early retinal development. J Neurosci, 2010. 30(11): p. 4110-9.

157. Murali, D., et al., Distinct developmental programs require different levels of Bmp signaling during mouse retinal development. Development, 2005. 132(5): p. 913-23.

158. Westenskow, P., S. Piccolo, and S. Fuhrmann, Beta-catenin controls differentiation of the retinal pigment epithelium in the mouse optic cup by regulating Mitf and Otx2 expression. Development, 2009. 136(15): p. 2505-10.

159. Liu, C., et al., Regulation of retinal progenitor expansion by Frizzled receptors: implications for microphthalmia and retinal coloboma. Hum Mol Genet, 2012. 21(8): p. 1848-60.

160. Sasagawa, S., et al., Axes establishment during eye morphogenesis in Xenopus by coordinate and antagonistic actions of BMP4, Shh, and RA. Genesis, 2002. 33(2): p. 86-96.

161. Matt, N., et al., Retinoic acid-dependent eye morphogenesis is orchestrated by neural crest cells. Development, 2005. 132(21): p. 4789-800.

162. Svoboda, K.K. and K.S. O'Shea, An analysis of cell shape and the neuroepithelial basal lamina during optic vesicle formation in the mouse embryo. Development, 1987. 100(2): p. 185-200.

163. Eiraku, M., et al., Self-organizing optic-cup morphogenesis in three-dimensional culture. Nature, 2011. 472(7341): p. 51-6.

164. Nicolas-Perez, M., et al., Analysis of cellular behavior and cytoskeletal dynamics reveal a constriction mechanism driving optic cup morphogenesis. Elife, 2016. 5.

165. Kemerley, A., et al., A novel mutation in ACTG1 causing Baraitser-Winter syndrome with extremely variable expressivity in three generations. Ophthalmic Genet, 2016: p. 1-5.

166. Bogdanovic, O., et al., Numb/Numbl-Opo antagonism controls retinal epithelium morphogenesis by regulating integrin endocytosis. Dev Cell, 2012. 23(4): p. 782-95.

167. Picker, A., et al., Dynamic coupling of pattern formation and morphogenesis in the developing vertebrate retina. PLoS Biol, 2009. 7(10): p. e1000214.

168. Heermann, S., et al., Eye morphogenesis driven by epithelial flow into the optic cup facilitated by modulation of bone morphogenetic protein. Elife, 2015. 4.

169. Sidhaye, J. and C. Norden, Concerted action of neuroepithelial basal shrinkage and active epithelial migration ensures efficient optic cup morphogenesis. Elife, 2017. 6.

170. Holt, C., Cell movements in Xenopus eye development. Nature, 1980. 287(5785): p. 850-2.

171. Pei, Y.F. and J.A. Rhodin, The prenatal development of the mouse eye. Anat Rec, 1970. 168(1): p. 105-25.

172. Dhomen, N.S., et al., Absence of chx10 causes neural progenitors to persist in the adult retina. Invest Ophthalmol Vis Sci, 2006. 47(1): p. 386-96.

173. Kim, T.H., et al., Phactr4 regulates neural tube and optic fissure closure by controlling PP1-, $R b$-, and E2F1-regulated cell-cycle progression. Dev Cell, 2007. 13(1): p. 87-102.

174. Kwan, K.M., et al., A complex choreography of cell movements shapes the vertebrate eye. Development, 2012. 139(2): p. 359-72.

175. Mann, I.C., The Development of the Human eye. 1928, [S.I.]: [s.n.].

176. Pagon, R.A., Ocular coloboma. Surv Ophthalmol, 1981. 25(4): p. 223-36.

177. James, A., et al., The hyaloid vasculature facilitates basement membrane breakdown during choroid fissure closure in the zebrafish eye. Dev Biol, 2016. 419(2): p. 262-272.

178. Geeraets, R., An electron microscopic study of the closure of the optic fissure in the golden hamster. Am J Anat, 1976. 145(4): p. 411-31. 
179. Hero, I., The optic fissure in the normal and microphthalmic mouse. Exp Eye Res, 1989. 49(2): p. 229-39.

180. Rolo, A., et al., Regulation of cell protrusions by small GTPases during fusion of the neural folds. Elife, 2016. 5: p. e13273.

181. Gage, P.J., et al., Fate maps of neural crest and mesoderm in the mammalian eye. Invest Ophthalmol Vis Sci, 2005. 46(11): p. 4200-8.

182. Morcillo, J., et al., Proper patterning of the optic fissure requires the sequential activity of BMP7 and SHH. Development, 2006. 133(16): p. 3179-90.

183. Molotkov, A., N. Molotkova, and G. Duester, Retinoic acid guides eye morphogenetic movements via paracrine signaling but is unnecessary for retinal dorsoventral patterning. Development, 2006. 133(10): p. 1901-10.

184. Lupo, G., et al., Retinoic acid receptor signaling regulates choroid fissure closure through independent mechanisms in the ventral optic cup and periocular mesenchyme. Proc Natl Acad Sci U S A, 2011. 108(21): p. 8698-703.

185. Tsuji, N., et al., Organogenesis of mild ocular coloboma in FLS mice: failure of basement membrane disintegration at optic fissure margins. Exp Eye Res, 2012. 94(1): p. 174-8.

186. See, A.W. and M. Clagett-Dame, The temporal requirement for vitamin A in the developing eye: mechanism of action in optic fissure closure and new roles for the vitamin in regulating cell proliferation and adhesion in the embryonic retina. Dev Biol, 2009. 325(1): p. 94-105.

187. Ozeki, H., et al., Apoptosis is associated with formation and persistence of the embryonic fissure. Curr Eye Res, 2000. 20(5): p. 367-72.

188. Bozanic, D., R. Tafra, and M. Saraga-Babic, Role of apoptosis and mitosis during human eye development. Eur J Cell Biol, 2003. 82(8): p. 421-9.

189. Gage, P.J., E.A. Hurd, and D.M. Martin, Mouse Models for the Dissection of CHD7 Functions in Eye Development and the Molecular Basis for Ocular Defects in CHARGE Syndrome. Invest Ophthalmol Vis Sci, 2015. 56(13): p. 7923-30.

190. Van Nostrand, J.L., et al., Inappropriate $p 53$ activation during development induces features of CHARGE syndrome. Nature, 2014. 514(7521): p. 228-32.

191. Vannahme, C., et al., Characterization of SMOC-1, a novel modular calcium-binding protein in basement membranes. J Biol Chem, 2002. 277(41): p. 37977-86.

192. Klemencic, M., et al., The heparin-binding activity of secreted modular calcium-binding protein 1 (SMOC-1) modulates its cell adhesion properties. PLoS One, 2013. 8(2): p. e56839.

193 Y.Xue, et. al., Embryonic lethality and vascular defects in mice lacking the Notch ligand Jagged1, Hum. Mol. Genet., 8 (5) (1999) 723-730 